\title{
An Automotive Thermoelectric-photovoltaic Hybrid Energy System
}

\author{
Xiaodong Zhang, K. T. Chau, C. C. Chan, and Shuang Gao \\ Department of Electrical and Electronic Engineering \\ The University of Hong Kong \\ Hong Kong \\ xiaodong@eee.hku.hk
}

\begin{abstract}
In recent years, there has been active research on exhaust gas waste heat energy recovery for automobiles. Meanwhile, the use of solar energy is also proposed to promote on-board renewable energy and hence to improve their fuel economy. In this paper, a new thermoelectric-photovoltaic hybrid energy system is proposed and implemented for automobiles. The key is to newly develop the power conditioning circuit using maximum power point tracking so that the output power of the proposed hybrid energy system can be maximized. An experimental system is prototyped and tested to verify the validity of the proposed system.
\end{abstract}

Keywords- hybrid energy system; thermoelectric; photovoltaic; maximum power point tracking

\section{INTRODUCTION}

With ever increasing oil consumption and growing concern on environmental protection, there is a pressing need to develop green energy sources for automobiles, including the waste heat energy recovery system [1]-[2] and solar energy system [3]-[5]. These kinds of energy sources can be used to online feed various automotive electronics or charge the battery for storage, hence reducing the oil consumption and the carbon emission of the automobiles.

Benefited from the photovoltaic effect and the Seebeck effect respectively, the photovoltaic (PV) panels and thermoelectric (TE) modules can directly convert the solar energy and heat energy to electrical energy [6]. As a relatively mature technology, the PV generator (PVG) has already been wildly employed in many fields and in many years, while the TE generator (TEG) has more restraints only for the application with sufficient heat sources or waster heat sources. However, the TEG has unique advantages of being maintenance free, silent in operation, independent on weather or topography and involving no moving and complex mechanical parts, compared with other power generators like gasoline motor-generator, hydropower generator and wind turbine [7]-[13]. In the past years, many applications have been reported on the TEG, such as the aerospace industry [14], automobile [15], waste incineration plants [16], central heating systems in cold city [17], and stove-top generators in remote country area [18], where the PVG can also been applied.
The concept of energy hybridization has been accepted for electrical vehicles (EVs) and hybrid electrical vehicles (HEVs) [19], [20]. Compared with individual energy sources, the hybrid energy system can offer some definite advantages for automobiles, namely the higher fuel economy due to the increase of on-board renewable energy, the better energy security due to the use of multiple resources, and the higher control flexibility due to the coordination for charging the same pack of batteries [21], [22]. So, the thermoelectric-photovoltaic (TE-PV) hybrid energy system is promising for all kinds of automobiles propelled by internal combustion engines (ICEs).

A number of topologies of power conditioning circuits (PCS) for small scale power generators have been proposed in the last decades [23]-[28]. For example, several dc-dc converter topologies have been proposed for TE conversion, such as the Ćuk converter, the SEPIC converter and the boost-buck cascade converter [29], [30]. However, these topologies can not meet the requirements of the hybrid energy sources [31], [32]. The multiple-input converters (MICs) can be used to interface the energy sources and the load as the power conditioning circuit [33]. This class of DC-DC converters can simultaneously handle multiple inputs, and regulate the output voltage or current.

In this paper, a new TE-PV hybrid energy system with the Ćuk-Ćuk MIC is proposed and implemented. The keys of this hybrid energy system are to harvest the waste heat energy of the ICE by the TEG so as to improve the fuel economy, and to convert the solar energy by the PVG so as to utilize the onboard renewable energy. Compared with the SEPIC-SEPIC MIC [21], the Ćuk-Ćuk MIC can offer non-pulsating input current and output current, which can significantly minimize the disturbance on system operation, and potentially enhance the battery life [34]. Furthermore, the Ćuk-Ćuk MIC needs three inductors while the SEPIC-SEPIC MIC needs four inductors, leading to lower cost, lighter weight and smaller volume. In Section II, the system configuration of the proposed TE-PV hybrid energy system will be described. Section III will be devoted to presenting the design and implementation of the proposed PCS with the maximum power point tracking (MPPT) controller. In Section IV and V, the implementation and detailed experimental results will be given to verify the validity of the proposed hybrid energy system. Finally, a conclusion will be drawn in Section VI. 


\section{SYSTEM CONFIGURATION}

Fig. 1 shows the system configuration of the proposed TEPV hybrid energy system for automotive application. This hybrid system is composed of a TEG branch, a PVG branch, a MPPT controller, a Cuk-Ćuk MIC, and a battery. In practice, the MPPT controller measures the output voltages and currents of the TEG and PVG, respectively, and generates the switching signals to the Ćuk-Ćuk MIC according to the MPPT algorithm. The controller also monitors the terminal voltage and body temperature of the battery. In case of overvoltage or overheat, the MIC is switched off to protect the battery.

The TEG is used to harvest the waste heat of the exhaust gas from the ICE. There are two main accessible waste heat sources, namely the radiator system and the exhaust gas system. The radiator system functions to pump the coolant through the chambers in the heat engine block so as to absorb the excess heat and draw it away, hence avoiding the engine block overheating and seizure. On the other hand, the exhaust gas system functions to emit the flue gas which occurs as a result of the combustion of fuels in the ICE. Currently, the TEG is mostly installed in the exhaust gas system because this configuration is easy to be implemented and has less influence on the operation of the engine. According to the temperature distribution of the exhaust gas system, a proper TE material can readily be determined. Also, the cooling system of the TEG can share with the engine cooling loop to further increase the output power.

For the PVG, the PV panels can be installed on the vehicle roof. In general, the vehicle roof area that can accommodate the $\mathrm{PV}$ panels ranges from about $1.5 \mathrm{~m}^{2}$ for a passenger car to about $30 \mathrm{~m}^{2}$ for a bus. So, by connecting a proper number of PV panels in series and in parallel, the PVG is able to provide the desired voltage and current ratings for the proposed system.

In this paper, the TE-PV hybrid energy system is used to charge the battery. When the battery voltage is lower than a preset minimum value $V_{b a t, \min }$, and the input voltage of the TEG or PVG branch is higher than the corresponding minimum value $V_{T E \text {, min }}$ or $V_{P V \text {, min }}$, the charging process is activated. When the maximum voltage $V_{b a t, \max }$ is reached, the battery is regarded as fully charged.

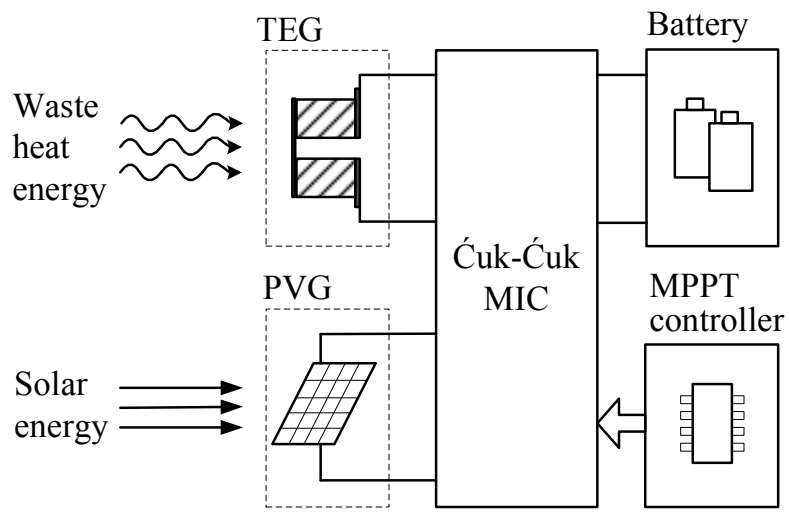

Fig. 1. Proposed TE-PV hybrid energy system.

\section{PROPOSED POWER CONDITIONING SYSTEM}

The Ćuk converter is selected for power conditioning of the TEG and PVG. First, the output voltage of the TEG or PVG may widely and dynamically vary with external physical factors. The Ćuk converter having both step-up and step-down characteristics can handle a wide range of input voltage variation caused by different temperature differences and insolation levels. Second, when the switch is turned off, the Cuk converter can inherently block the DC input from the TEG or PVG energy sources to the load due to the existence of the intermediate capacitor. Third, both of the input current and output current of the Ćuk circuit are non-pulsating. By properly winding the input and output inductors on the same core, the ripple amplitude can be reduced to zero. This merit can significantly minimize the disturbance on the TEG or PVG operating points, and potentially enhance the battery life.

Based on the synthesizing principles of the MIC, two Cuk circuits are lumped together to form a Ćuk-Ćuk MIC as shown in Fig. 2. This MIC not only retains the merits of the Cuk circuit, but also enables the TEG and PVG delivering the power to the load individually or simultaneously. Furthermore, it can be illustrated that the MPPT method previously proposed for single source system can be directly applied for this CukĆuk MIC for hybrid energy system.

The Cuk converter can be operated in three modes: continuous current mode (CCM), discontinuous inductor current mode (DICM), and discontinuous capacitor voltage mode (DCVM). Generally, the CCM is more suitable for high voltage, high current input application; the DICM is for high voltage, low current input application; and the DCVM is for low voltage, high current input application. Since the TEG and PVG are of low output voltage, hence low input voltage for the Ćuk-Ćuk MIC, it is preferred to operate in the DCVM mode.

When the two input inductors $L_{11}, L_{12}$, the output inductor $L_{21}$ and the output capacitor $C$ are large enough to guarantee that the inductor currents $I_{11}, I_{12}, I_{21}$ and the output voltage $V_{B}$ are constant, the topological stages of the Cuk-Ćuk MIC charging the battery in the DCVM are depicted in Fig. 3.

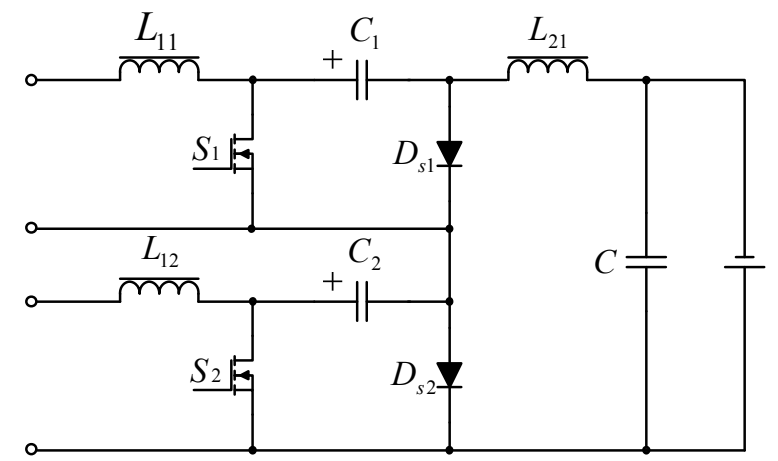

Fig. 2. Proposed Ćuk-Ćuk MIC. 


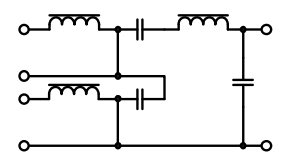

(1)

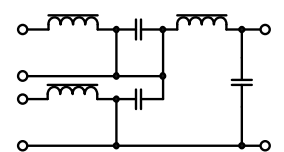

(2)

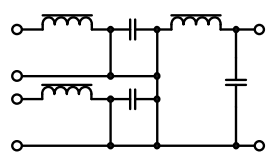

(3)

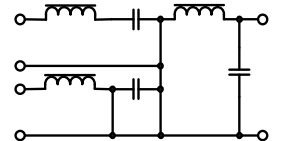

(4)

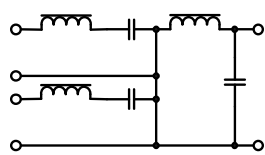

(5)
Fig. 3. Topological stages in DCVM.

Since the output power characteristics of the TEG are highly nonlinear and heavily depend on the heat source, cooling system and external load, a PCS circuit and MPPT control are required. Similarly, the PVG output power characteristics heavily depend on the irradiance, ambient temperature and external load. So, the proposed PCS circuit needs MPPT control. By using the Thevenin transformation, the equivalent circuit of the TEG and PVG can separately be represented by a DC voltage source in series with an internal resistance. So the PCS functions to track the maximum power point of the TEG or PVG. By tuning the duty cycle of its PWM switching signal to enable the input resistance $r_{i}=V_{i} / I_{i}$ equal to the internal resistance of the energy source $r_{g}$, the MPPT can be performed.

\section{IMPLEMENTATION}

The proposed TE-PV hybrid energy system with the MPPT control is implemented as shown in Fig. 4. The TEG is composed of 18 pieces of TE modules (Model TEP1-126560.6 ), an induction heater, and a heatsink. These modules are connected with 6 pieces electrically in series and 3 branches in parallel. On the other hand, the PVG is composed of 9 pieces of polycrystalline-silicon PV panels (Model SR10-36), and tungsten halogen lamps. These PV panels are connected electrically in parallel. A $12 \mathrm{~V} 38$ Ah lead-acid battery is selected as the battery load, which has an internal resistance of $7.5 \mathrm{~m} \Omega$. At the beginning of the experiment, the output characteristics of the TEG and PVG are measured at specific working conditions by changing the external load. Based on the measured characteristics of the TEG and PVG, the circuit components of the proposed Ćuk-Ćuk MIC can be designed. The switching frequency is set as $100 \mathrm{kHz}$. The microcontroller chip DSP2812 operates at $30 \mathrm{MHz}$ clock frequency, incorporating with 16 12-bit ADC channels, 18k 16-bit SRAM, and 16 PWM channels in two Event Managers. So, it can provide fast computing speed, precise $\mathrm{A} / \mathrm{D}$ conversion, and user-friendly programmable PWM generation. Thus, it is adopted as the MPPT controller.

Although different MPPT methods have been proposed, the perturb-and-observe (PAO) method is still the most common one in practice due to its simplicity and system independence. Thus, the proposed MIC adopts this method to perform the MPPT for both the TEG and PVG branches of the hybrid energy systems.

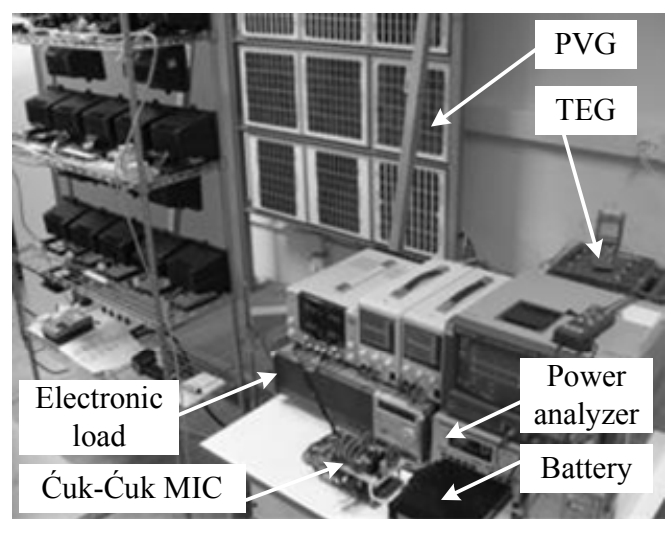

Fig. 4. System prototype.

\section{EXPERIMENTAL RESULTS}

Firstly, when the temperature of the cold-side of the TEG is kept at $50{ }^{\circ} \mathrm{C}$, the output power of the TEG at different hotside temperatures is recorded by changing the load resistance from $3 \Omega$ to $15 \Omega$ as shown in Fig. 5. It can be found that the output characteristics vary non-linearly with the temperature and load. Secondly, with the surface temperature of the PVG kept at $40{ }^{\circ} \mathrm{C}$, the output power of the PVG at different irradiances is measured by changing the load resistance from 3 $\Omega$ to $15 \Omega$ as shown in Fig. 6. It can be found that the output characteristics vary non-linearly with the irradiance and load.

For verification, by tuning the duty cycle of each Ćuk branch, the MPPT of each branch can be achieved as shown in Fig. 7 and 8 . It can be found that the duty cycle of the TEG branch for the MPPT decreases with the increase of temperature, while the duty cycle drift of the PVG branch for the MPPT is contrary.

In order to quantitatively assess the output power improvement due to the MPPT, the TEG temperature is varied while the PVG output is kept at its maximum power point, and then the PVG irradiance is varied while the TEG output is kept at its maximum power point. Firstly, the output power is recorded when the hot-side temperature of the TEG is heated from $100{ }^{\circ} \mathrm{C}$ to $250{ }^{\circ} \mathrm{C}$ and the irradiance of the PVG is fixed at $1000 \mathrm{~W} / \mathrm{m}^{2}$. For the sake of comparison, the output power is also measured under the fixed duty cycle of $67 \%$, which is close to the duty cycle of the maximum power point at $250{ }^{\circ} \mathrm{C}$. As shown in Fig. 9, the power improvement is from $7.5 \%$ to $9.4 \%$ due to the use of the MPPT. Secondly, the total output power is recorded when the irradiance of the PVG is controlled from $200 \mathrm{~W} / \mathrm{m}^{2}$ to $1000 \mathrm{~W} / \mathrm{m}^{2}$ and the hot-side temperature of the TEG is fixed at $250{ }^{\circ} \mathrm{C}$. For the sake of comparison, the output power is also measured under the fixed duty cycle of $75 \%$, which is close to the duty cycle of the maximum power point at $1000 \mathrm{~W} / \mathrm{m}^{2}$. As shown in Fig. 10, the power improvement is from $4.8 \%$ to $17.9 \%$ resulting from the use of the MPPT. Therefore, the overall output power of the hybrid energy system can be significantly improved by the proposed Ćuk-Cuk MIC using the MPPT. 


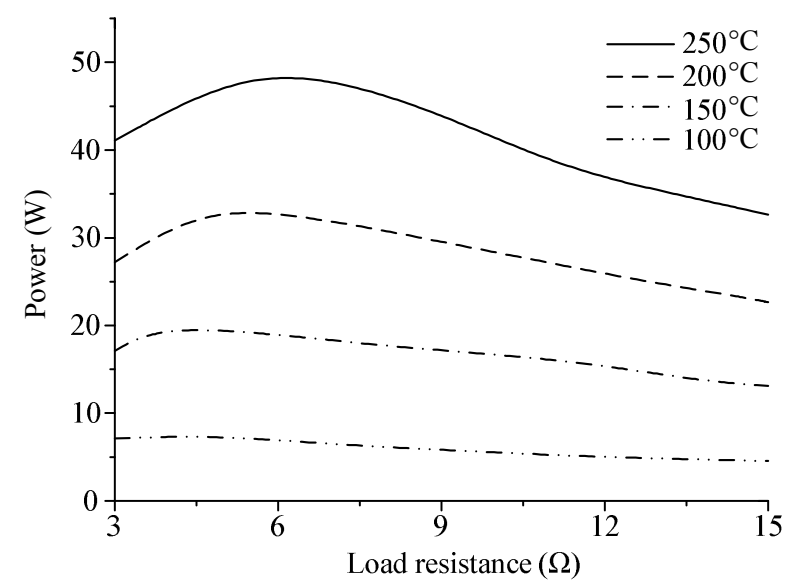

Fig. 5. Output power versus load resistance of the TEG.

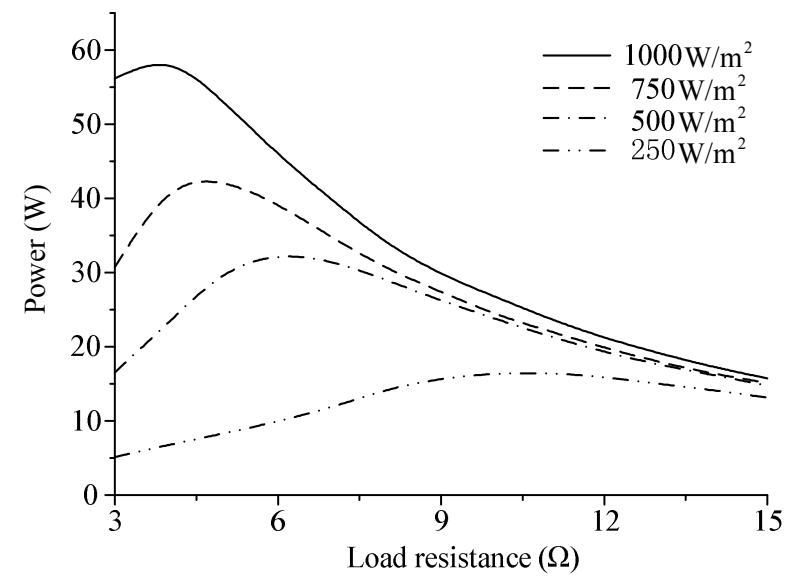

Fig. 6. Output power versus load resistance of the PVG.

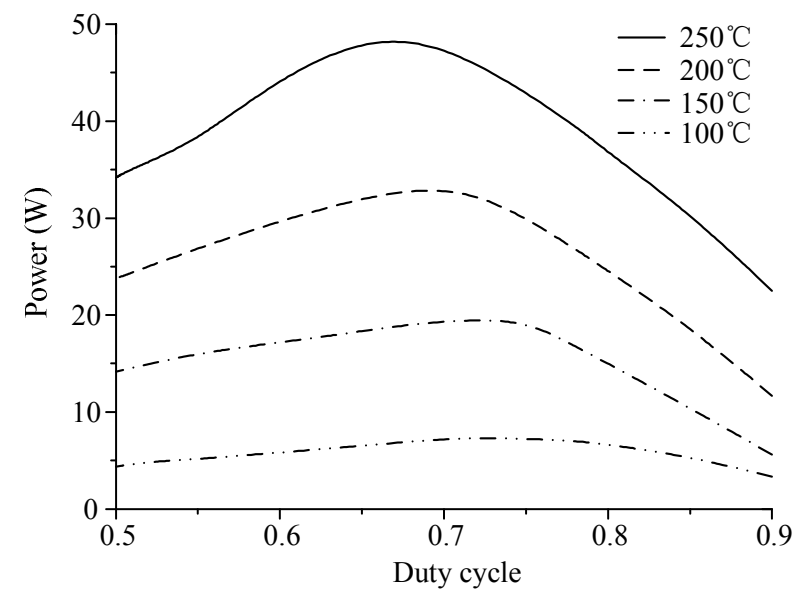

Fig. 7. Input powers of Ćuk TEG branch versus duty cycle.

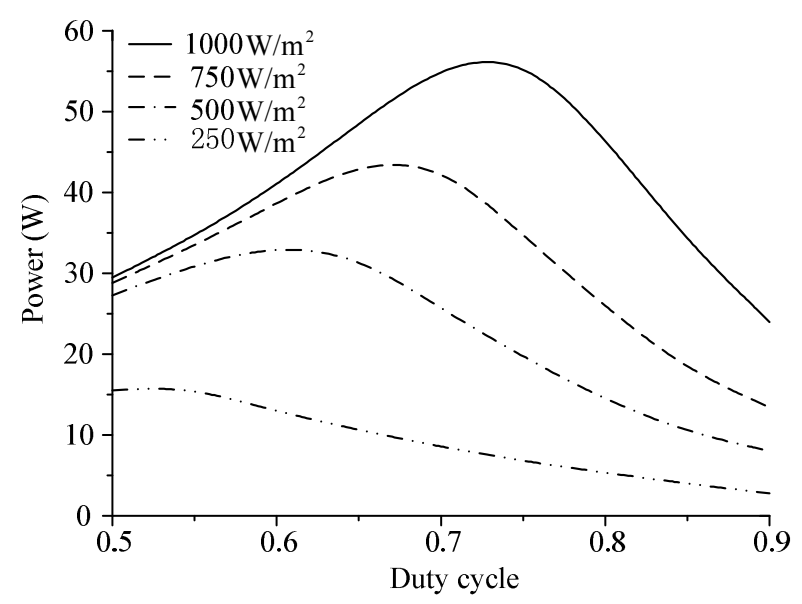

Fig. 8. Input powers of Ćuk PVG branch versus duty cycle.

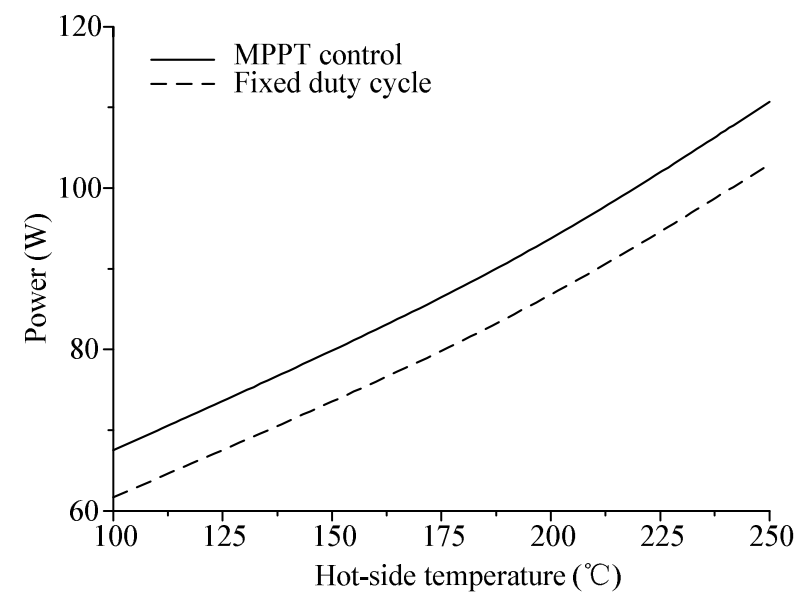

Fig. 9. Output power and power improvement with varying TEG output power.

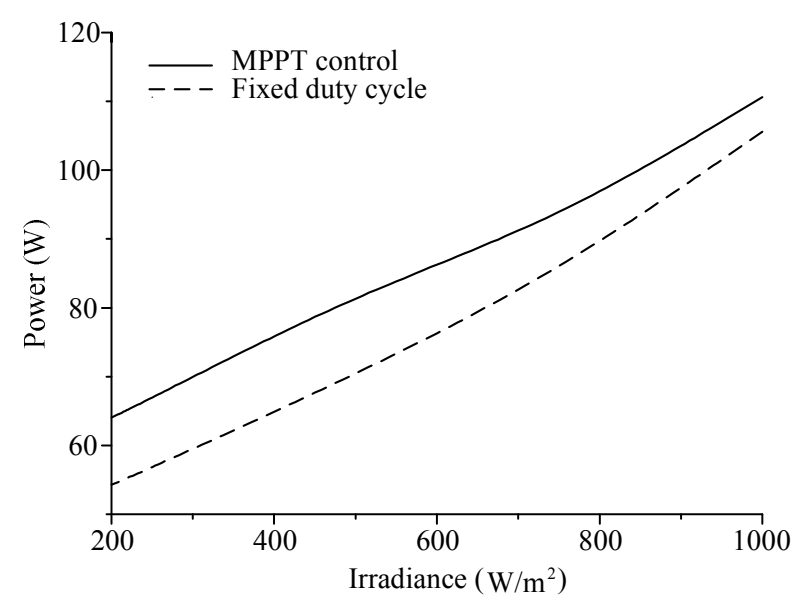

Fig. 10. Output power and power improvement with varying PVG output power. 


\section{CONCLUSIONS}

In this paper, a new automotive TE-PV hybrid energy system has been proposed and implemented. Based on the proposed Ćuk-Ćuk MIC with the MPPT, both the TEG and PVG branches can achieve maximum power transfer independently. A $100 \mathrm{~W}$ prototype has been built and tested.

\section{ACKNOWLEDGMENT}

This work was supported by a grant (Project code: 200807176032) from the Committee on Research and Conference Grants, The University of Hong Kong, Hong Kong Special Administrative Region, China.

\section{REFERENCES}

[1] J. Yang, "Potential applications of thermoelectric waste heat recovery in the automotive industry," International Conference on Thermoelectrics, June 2005, pp. 155-159.

[2] C. C. Chan and K. T. Chau, "An overview of power electronics in electric vehicles," IEEE Transactions on Industrial Electronics, vol. 44, no. 1, Feb. 1997, pp. 3-13.

[3] K. T. Chau and C. C. Chan, "Emerging energy-efficient technologies for hybrid electric vehicles," Proceedings of IEEE, vol. 95, no. 4, Apr. 2007, pp. 821-835.

[4] J. Schaefer, "Review of photovoltaic power plant performance and economics," IEEE Transactions on Energy Conversion, vol. EC-5, June 1990, pp. 232-238.

[5] K. T. Chau, Y. S. Wong and C. C. Chan, "An overview of energy sources for electric vehicles," Energy Conversion and Management, vol. 40, no. 10, July 1999, pp. 1021-1039.

[6] X. Zhang, K. T. Chau, C. Yu and C. C. Chan "An optimal solarthermoelectric hybrid energy system for hybrid electric vehicles," IEEE Vehicle Power and Propulsion Conference, Sep. 2008, pp. 1-6.

[7] K. T. Chau, C. C. Chan and C. Liu, "Overview of permanent-magnet brushless drives for electric and hybrid electric vehicles," IEEE Transactions on Industrial Electronics, vol. 55, no. 6, June 2008, pp. 2246-2257.

[8] C. Liu, K. T. Chau, J. Z. Jiang and L. Jian, "Design of a new outer-rotor permanent magnet hybrid machine for wind power generation," IEEE Transactions on Magnetics, vol. 44, no. 6, June 2008, pp. 1494-1497.

[9] Y. Fan, K. T. Chau and S. Niu, "Development of a new brushless doubly fed doubly salient machine for wind power generation," IEEE Transactions on Magnetics, vol. 42, no. 10, Oct. 2006, pp. 3455-3457.

[10] S. Niu, K. T. Chau, J. Z. Jiang and C. Liu, "Design and control of a new double-stator cup-rotor permanent-magnet machine for wind power generation," IEEE Transactions on Magnetics, vol. 43, no. 6, June 2007, pp. 2501-2503.

[11] K. T. Chau, Y. B. Li, J. Z. Jiang and S. Niu, "Design and control of a PM brushless hybrid generator for wind power application," IEEE Transactions on Magnetics, vol. 42, no. 10, Oct. 2006, pp. 3497-3499.

[12] S. Niu, K. T. Chau and C. Yu, "Quantitative comparison of double-stator and traditional permanent magnet brushless machines," Journal of Applied Physics, vol. 105, no. 7, Apr. 2009, paper no. 07F105, pp. 1-3.

[13] K. T. Chau, Y. B. Li, J. Z. Jiang and C. Liu, "Design and analysis of a stator-doubly-fed doubly-salient permanent-magnet machine for automotive engines," IEEE Transactions on Magnetics, vol. 42, no. 10, Oct. 2006, pp. 3470-3472.

[14] J. F. Mondt, M. L. Underwood and B. J. Nesmith, "Future radioisotope power needs for missions to the solar system," Proceedings of the 32nd Intersociety Energy Conversion Engineering Conference, July 1997, Vol. 1, pp. 460-464.

[15] K. Matsubara, "Development of a high efficient thermoelectric stack for a waste exhaust heat recovery of vehicles," International Conference on Thermoelectrics, Aug. 2002, pp. 418-423.
[16] A. Tsuyoshi, S. Kagawa, M. Sakamoto and K. Matsuura, "A study of commercial thermoelectric generation in a processing plant of combustible solid waste," International Conference on Thermoelectrics, Aug. 1997, pp. 555-558.

[17] M. D. Rowe, G. Min, S. G. K. Williams, A. Aoune, K. Matsuura, V. L. Kuznetsov and L. W. Fu, "Thermoelectric recovery of waste heat-case studies," Intersociety Energy Conversion Engineering Conference, July 1997, vol. 2, pp. 1075-1079.

[18] J. Eakburanawat and I. Boonyaroonate, "Development of a thermoelectric battery-charger with microcontroller-based maximum power point tracking technique," Applied Energy, vol. 83, no. 7, July 2006, pp. 687-704.

[19] K. T. Chau and Y. S. Wong, "Hybridization of energy sources in electric vehicles," Energy Conversion and Management, vol. 42, no. 9, June 2001, pp. 1059-1069.

[20] K. T. Chau and Y. S. Wong, "Overview of power management in hybrid electric vehicles," Energy Conversion and Management, vol. 43, no. 15, June 2002, pp. 1953-1968.

[21] X. Zhang, K. T. Chau and C. C. Chan, "Design and implementation of a thermoelectric-photovoltaic hybrid energy source for hybrid electric vehicles," World Electric Vehicle Journal, vol. 3, Dec. 2009, pp. 1-11.

[22] C. Liu, K. T. Chau and X. Zhang, "An efficient wind-photovoltaic hybrid generation system using doubly-excited permanent-magnet brushless machine," IEEE Transactions on Industrial Electronics, vol. 57, no. 3, Mar. 2010, pp. 831-839.

[23] C. C. Chan and K. T. Chau, "A new zero-voltage-switching dc/dc boost converter," IEEE Transactions on Aerospace and Electronic Systems, vol. 29, no. 1, Jan. 1993, pp. 125-134.

[24] K. T. Chau, "A new class of pulsewidth-modulated multi-resonant converters using resonant inductor freewheeling," International Journal of Electronics, vol. 77, no. 5, Nov. 1994, pp. 703-714.

[25] S. Z. Jiang, K. T. Chau and C. C. Chan, "Harmonic reduction in dc-link current of a dual-inverter pole-changing induction motor drive for electric vehicles," Electric Power Components and Systems, vol. 31, no. 11, Nov. 2003, pp. 1063-1081.

[26] C. C. Chan and K. T. Chau, "A fast and exact time-domain simulation of switched-mode power regulators," IEEE Transactions on Industrial Electronics, vol. 39, no. 4, Aug. 1992, pp. 341-350.

[27] C. C. Chan and K. T. Chau, "Spectral modeling of switched-mode power converters," IEEE Transactions on Industrial Electronics, vol. 41, no. 4, Aug. 1994, pp. 441-450.

[28] M. S. W. Chan and K. T. Chau, "A switched-capacitor boost-multilevel inverter using partial charging," IEEE Transactions on Circuits and Systems II, vol. 54, no. 12, Dec. 2007, pp. 1145-1149.

[29] X. Zhang, K. T. Chau and C. C. Chan, "Overview of thermoelectric generation for hybrid vehicles," Journal of Asian Electric Vehicles, vol. 6, no. 2, Dec. 2008, pp. 1119-1124.

[30] R. Y. Kim, and J. S. Lai, Aggregated modeling and control of a boostbuck cascade converter for maximum power point tracking of a thermoelectric generator, The 23rd Annual IEEE Applied Power Electronics Conference and Exposition, Feb. 2008, pp. 1754-1760.

[31] K. T. Chau, C. C. Chan, and Y. S. Wong, "Advanced power electronic drives for electric vehicles," Electromotion, vol. 5, no. 2, Apr.-June 1998, pp. 42-53.

[32] K. T. Chau and Z. Wang, "Overview of power electronic drives for electric vehicles," HAIT Journal of Science and Engineering - B: Applied Sciences and Engineering, vol. 2, no. 5-6, Dec. 2005, pp. 737761.

[33] Y. C. Liu and Y. M. Chen, A systematic approach to synthesizing multiinput DC/DC converters, IEEE Power Electronics Specialists Conference, June 2007, pp. 2626-2632.

[34] C. Yu and K. T. Chau, "Thermoelectric automotive waste heat energy recovery using maximum power point tracking," Energy Conversion and Management, vol. 50, no. 6, June 2009, pp. 1506-1512. 